\title{
Biomonitoring of organic and inorganic chemicals in the hair of Vietnamese people via spectral and chromatographic analysis
}

\author{
Le Phuoc Cuong $^{1^{*}}$, Le Thi Xuan Thuy ${ }^{1}$, Micheal Evgenev ${ }^{2}$ \\ ${ }^{1}$ Danang University of Technology, Danang, Vietnam; *Corresponding Author: le_p_cuong@mail.ru, lpcuong@dut.udn.vn \\ ${ }^{2}$ Kazan National Research Technological University, Kazan, Russia \\ Received 31 August 2012; revised 5 October 2012; accepted 19 October 2012
}

\begin{abstract}
A combination of spectral and chromatographic analytical methods has been executed to monitor chemicals in the hair of Vietnamese people. Methods were developed for the determination of some chemical elements in hair by inductively coupled-plasma atomic emission spectroscopy with limits of detection reaching $1-100 \mu \mathrm{g} \cdot \mathrm{I}^{-1}$. A supercritical fluid extraction (SFE) and clean-up procedures were established for isolating organochlorine pollutants (OCPs) and organophosphorus pesticides (OPPs) from the hair of the Vietnamese test subjects. Eight OCPs and OPPs were determined by SFE with carbon dioxide only and methanol-modified carbon dioxide extraction at 350 bar and $45^{\circ} \mathrm{C}$, followed by gas chromatography coupled to mass spectrometry. The results indicated that OCPs can be extracted quantitatively using $\mathrm{CO}_{2}$ only, whereas OPPs require a modifier for extraction. The limits of detection that were found were between 0.7 to $1.3 \mu \mathrm{g} \cdot \mathrm{g}^{-1}$, and good linearity $\left(r^{2}>0.9861\right)$ was achieved within the tested ranges. The activities of the $\mathrm{N}$-acetyltransferase (NAT) and the monooxygenases cytochrome P450 (CYP450) were determined and compared to the acetylation and oxidation phenotypes of healthy Vietnamese test subjects. The variations in the concentration of chemical elements in human hair were shown to be dependent upon the activities of the twophase metabolic system, on the individual's gender and the duration of residence within Russia.
\end{abstract}

Keywords: NAT; CYP450; Pesticides; Chemical Elements; ICP-AES; SFE-GC/MS

\section{INTRODUCTION}

The increased growth of the development of the che- mical industry is directly correlated with a very strong negative impact of human activities on our environment. The most wide-scale and influential of these is the chemical pollution of the environment by xenogenic artificial chemical substances. Additional factors include: toxic chemical elements, organic pesticides and other substances of industrial and household genesis [1-3]. These pollutants remain in the ecological nutritional chains for an extended period of time, which leads to a rise in a number of acute and chronic diseases (cancer, Alzheimer's disease, Parkinson's disease) [4,5]. As a result, the issue of monitoring the chemical xenobiotics in the environment and in human organs is necessary.

The main factor in determining the body's individual sensitivity to the impact of toxic chemical substances is genetic predisposition. Therefore, it is very important to find an answer to the human ecology problems and determine the methods of monitoring the xenobiotics biotransformation-related allelically determined processes within the human body. This is vital because of the significant differences in ecotoxic action of chemical substances, which give reason for polymorphism of their metabolic processes. With respect to ecology, determining biochemical phenotypes of toxicants metabolism of industrial personnel and other people is necessary for the assessment of risks of intoxication, oncogenesis, individual chemical sensitivity, occupational fitness, uncovering groups of heightened risk and to lessen the development of unfavorable ecological factors. The impact of ecological factors may lead to an increase in the inherited numbers of pathologies, which are the root of many different ailments related to metabolic disorders $[2,6]$.

The process of transforming lipophilic xenobiotics (toxic chemical elements, compounds) to polar entities occurs in two distinct metabolic phases. During the first phase, the foreign substance is modified through chemical reactions that add polar or reactive groups to its molecules. The most prominent group of proteins involved in this phase is the cytochrome P450 (CYP450) 
family, which encompasses more than 11,500 different proteins and is present in all forms of life on Earth. The modified xenobiotic is then detoxified through reactions with other molecules during the second phase, combining with them to form molecules called xenobiotic conjugates. These types of reactions are catalysed by transferase enzymes such as N-acetyltransferase (NAT). The acetylation polymorphism is associated with an increased risk of chemical compounds toxicity (chemical elements, pesticides) and with an increased frequency of certain cancers. Therefore, people with the phenotypes of slow $\mathrm{N}$-acetylation will have a higher risk of chemical toxins wihin the tissues and cells [7].

A lack of vitally important elements in drinking water, industrial pollution of the environment with toxic and radioactive elements, poor nutrition, diseases and certain harmful pharmaceuticals all may lead to ailments derived from deficiency, excessiveness or an improper balance of microelements within the human body. In order to assess the level of microelements within the human body and other diagnostic biological substrata, such as blood, urine and nails - hair is used as well $[8,9]$.

Hair possesses cumulative characteristics, so its composition reflects general conditions of human health. As a result, hair is a traditional biological material used in ecological and epidemiological surveys. Furthermore, it is a convenient diagnostic substratum for screening large groups of people. Collecting samples of hair is safe for human health, and preliminary studies of hair can involve large groups of subjects. However, there is one important peculiarity of hair-its ability to absorb endogenic substances from a human organism and preserve them in a practically invariable state for an extended length of time (ranging from several months to several years) $[10,11]$.

The usage of liquid-liquid extraction (LLE) is a classical approach to extracting pesticides from water samples as a result of hair degeneration. However, the process of LLE requires large amounts of toxic solvents and is very time consuming (Table 1). It is also essential to notice the negative effects that often take place during evaporation - concentration of chemical impurities from the solvent that finally leads to the deviation of the probe's chemical compound. While examining ways to eliminate the abovementioned inadequacies, much attention has been paid to the process of supercritical fluid extraction over the past several years. First and foremost, is the use of carbon dioxide. SFE is an ecologically safe, thrifty and speedy method of extraction of organic substances from different biological objects [12-20].

During the testing phase, we developed complex ecological analysis methods for chemical elements and organic pesticides to monitor the human hair, and to rese-
Table 1. Certain regimen parameters and results of SFE and LLE processes used in extracting DDT from the hair of Vietnamese test subjects $(n=5)$.

\begin{tabular}{cccccc}
\hline Method & Volume of & \multirow{2}{*}{$\mathrm{T},{ }^{\circ} \mathrm{C}$} & $\mathrm{P}, \mathrm{bar}$ & Time, hour & \% Recovery \\
\cline { 1 - 2 } of extraction & solvent, $\mathrm{ml}$ & & & & \\
\hline LLE & $20-40$ & 25 & 1 & $40^{* *}$ & $70 \pm 11$ \\
SFE & $7-10^{*}$ & 45 & 350 & 1 & $85 \pm 13$ \\
\hline
\end{tabular}

Includes the volume of co-solvent $\mathrm{MeOH} ;{ }^{* *}$ Includes the time of digestion in $3 \mathrm{M} \mathrm{HCl}$.

arch genetically determined processes of xenobiotics biotransformation within the human organism. The monooxygenase CYP 450 are responsible for approximately $75 \%$ of the metabolism of different pharmaceuticals and chemical substances [20]. Based on the activity of N-acetyltransferase NAT in the organism, test subjects care able to be subdivided into groups with the phenotypes of slow and rapid N-acetylation. Distribution based on phenotypes varies between different racial and ethnic groups. However, there is no such data for the Vietnamese population [7].

\section{EXPERIMENT}

\subsection{Materials}

The chemicals used as analytical standards were all reagent-grade or higher. Hexachlorobenzene, p,p'DDT, p,p'DDE, butapon, 2,4-D, lindane, chlorofos, dichlorvos were purchased from "Metrologia + Scientific and Production Company" Ltd. (Russia). Standard chemical elements with concentrations from 0.5 to $2 \mathrm{ppm}$ were obtained from "Skat" (Novosibirsk, Russia). As standard samples for providing adequacy and reliability of quantitative chemical analysis, a series of standard pesticides solutions with concentrations of 10,50,100,150, 200 $\mathrm{ng} \cdot \mathrm{g}^{-1}$, respectively, and a standard hair sample GSH were used. As biomarkers, isoniazid (Russia) in the form of $0.3 \mathrm{~g}$ pills and antipirine (Belgium) in the form of powder were used. All of the solvents (methanol, n-hexane, acetone, dichloromethane) used were supplied by Chimreaktiv (Moscow, Russia). During the process of supercritical fluid extraction, the edible carbon dioxide (99.8\%) passed through a filter-drier where dehydrated silica gel was used. Also, ultra pure water obtained from a Simplicity-185 purifier system (Millipore Corp., France) was used. All glassware and polyethylene bottles were thoroughly washed and then soaked in nitric acid and rinsed with ultra pure water before use.

\subsection{Apparatus}

The process of supercritical fluid $\mathrm{CO}_{2}$-extraction from the hair samples was conducted with the assistance of a supercritical fluid extraction instrument of circulatory 
type with fluid pumps provided by Thar Technologies Inc. company (USA).

The chromato-mass-spectrometric analysis was performed by the DFS Thermo Electron Corporation (USA). The specters of chemicals absorption were registered by a spectrophotometer SF-26 (Lomo, Russia).

Concentrations of 28 chemical elements were determined in the hair samples by using the inductively coupled plasma atomic emission spectroscopy (ICP-AES) iCAP 6300 DUO (Thermo Scientific, USA). In the spectrometer, the Echelle optical arrangement and the semiconductor CID-detector were used. The spectrometer design ensured simultaneous measurement of analytical lines within the range of 166 to $867 \mathrm{~nm}$, respectively. The optical resolution was less than $0.007 \mathrm{~nm}$ with a wavelength of $200 \mathrm{~nm}$, which gave us the possibility to analyze materials with the most compound specters. The spark inductor frequency was $27.12 \mathrm{MHz}$. The microwave system "speedwave MWS-3" (Germany) was used for hair digestion with a temperature program in the high-pressure reservoir.

\subsection{Sampling}

A sample size of 65 biological liquids (urine, saliva) were taken from healthy Vietnamese test subjects including 35 urine probes for estimation of NAT activity and 30 saliva probes for estimation of CYP 450 activity.

The hair samples were voluntarily collected from 65 Vietnamese test subjects. The subjects were divided into 2 groups: group 1:40 from Kazan, who have been living in Russia for 10 to 25 years; and group 2:25 from Danang and Ho Chi Minh cities, Vietnam. The hair samples were cut close to the scalp with stainless steel scissors (that were rinsed with acetone before use) and were placed into identified paper envelopes for further analysis. The urine, saliva and hair samples were collected from the same subjects.

\subsection{Methods}

\subsubsection{The Method of Determining Activity of Fermentative System for Xenobiotics Metabolism}

Method of acetylation phenotyping. During this investigation, the method of phenotyping by izoniazide consisted in determining free izoniazide, with the help of isonicotinic acid hydrazide complex (INH) with ammonium metavanadate in the urine, after oral administration of a test dose of the substance $-6 \mathrm{mg} \cdot \mathrm{kg}^{-1}$. Spectrophotometric measurement was made by the spectrophotometer SF-26 with a wavelength of $420 \mathrm{~nm}$. A $0.3 \mathrm{~g}$ dose of izoniazide is administrated orally to an examinee. Urine was collected every two hours during a period of six hours after the test-marker administration. In hourly urine probes, concentration of INH was determined with the help of spectrophotometric measurement. Based on the gathered data, kinetic curves were built, the INH dose fraction was measured, and the acetylizing phenotype was assessed. For measuring the INH concentration, 0.3 $\mathrm{ml}$ of urine was added to $7.7 \mathrm{ml}$ of distilled water and 2 $\mathrm{ml}$ of $0.2 \%$ ammonium metavanadate solution in $10 \%$ sulphuric acid. The amount of produced INH was determined via the calibration curve.

Method of oxidation phenotyping. For phenotyping the oxidation processes, the antipyrine test has acquired extensive practical application. The reaction of interaction of antipyrine with sodium nitrite in acidic medium has been well explored and is widely used in executing the antipyrine test. The product of such interaction is the nitrous antipyrine, with its emerald green color. Spectrophotometric measurement was made by the spectrophotometer SF-26, with a wavelength of $360 \mathrm{~nm}$. Antipyrine was taken in on a single occasion orally, in the amount of $0.6 \mathrm{~g}$ in the morning and on an empty stomach. Saliva was gathered every three hours during a 12-hour period. For particulate contamination, saliva was centrifugalized during a period of ten minutes. Moreover, $4 \mathrm{ml}$ of supernatant fluid, $4 \mathrm{ml}$ of distilled water, $4 \mathrm{ml}$ of zink agent (100 $\mathrm{g} \mathrm{ZnSO}_{4}$ was dissolved in $1 \mathrm{~L}$ of $1.2 \%$ sulphuric acid solution), $4 \mathrm{ml}$ of $0.75 \mathrm{M}$ potassium hydroxide (in drops) were put into test tubes. The solution was shaken for a period of 30 seconds. Furthermore, centrifugation was completed during a 15-minute period. 3 $\mathrm{ml}$ of pure supernatant fluid of each sample was put into additional test tubes and placed into a thermostat for five minutes at the temperature of $25^{\circ} \mathrm{C}$. Afterwards, without withdrawing the probes from the thermostat, $0.1 \mathrm{ml}$ of 4 $\mathrm{M}$ sulphuric acid and $0.2 \mathrm{ml}$ of $0.2 \%$ sodium nitrite solution was introduced. Incubation was continued throughout a 20-minute period. Furthermore, optical density was measured by the spectrophotometer with a wavelength of $360 \mathrm{~nm}$. The amount of produced antipyrine was determined by the calibration curve. The amount of antipyrine produced with saliva during a 12-hour period was calculated. Reactions of biomarkers in urine and in saliva with chemical reagents are shown in Figure 1.

\subsubsection{The Method of Determining Chemical Elements in Human Hair}

To achieve reproducible results, the sample selection was executed on the occipital lobe of the test subject's head on a similar spot from the hair baseline, in the amount of no less than 200 - $250 \mathrm{mg}$, respectively. The hair was then put into a Petri dish and rinsed in $20 \mathrm{ml}$ of acetone, then rinsed twice in $40 \mathrm{ml}$ of bidistilled water, and then once more in $20 \mathrm{ml}$ of acetone. After rinsing, the hair was dried under a temperature of $80^{\circ} \mathrm{C}$ until its mass became constant. In order to find chemical elements, 


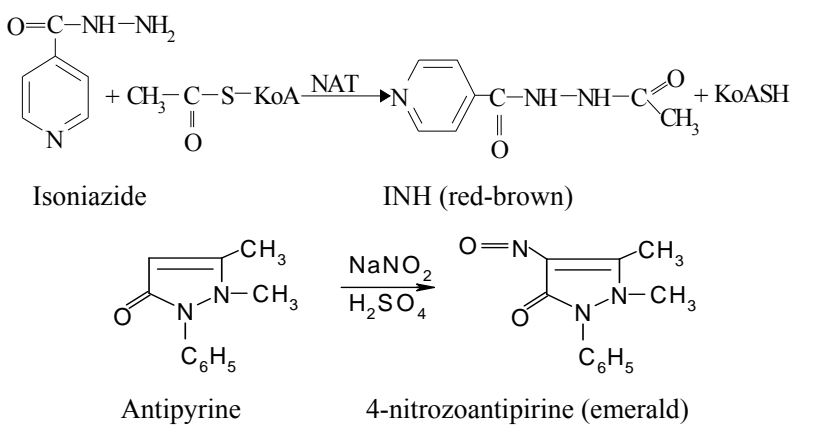

Figure 1. Reactions of biomarkers in urine (isoniazide) and in saliva (antipyrine) with chemical reagents.

each hair sample, weighing approximately $200 \mathrm{mg}$, was placed into a high-pressure reservoir DAP-60+ (BERGHOF) made from TFM. The reservoir was filled with $50 \mathrm{ml}$ of $65 \% \mathrm{HNO}_{3}$ and airproofed with a tip with a special impermeable edge. The pressure reservoirs with hair were then subjected to hydrolysis in the speedwave MWS-3+ microwave system (Germany) with a temperature program that is shown Table 2.

In the hair samples, concentration of 28 chemical elements (Ag, Al, B, Ba, Ca, Cu, Fe, K, Mg, Mn, Ni, Pb, Zn, Cr, Co, Ga, Li, Mo, Na, Cd, P, Se, Si, Sn, Sr, Ti, V, W) was calculated with the help of atomic emission spectrometry with inductively coupled argon plasma iCAP 6300 DUO (Thermo Scientific, USA). The calibration curves that connect the analyte concentration in plasma with the instrumental response were linear in the range of five exponents of concentration value. For investigated elements, the limits of determining are $1-100 \mu \mathrm{g} \cdot l^{-1}$, respectively.

The measurements were executed five separate times, after which the results were averaged out. The relative measurement error, consisting of accidental errors during the dissolving phase and choice errors, was no more than $10 \%$. The correlation parameter for each element was no worse than 0.98 .

The analysis was executed in axial mode. The capillar flushing time before analysis was 30 seconds. The pump velocity during flushing was $100\left(\mathrm{rev} \cdot \mathrm{min}^{-1}\right)$, during analysis was $50\left(\mathrm{rev} \cdot \mathrm{min}^{-1}\right)$, respectively. The flow of argon in the pulverizer and in the secondary flow was 0.7 $1 \cdot \mathrm{min}^{-1}$ and $0.51 \cdot \mathrm{min}^{-1}$, respectively. The power of plasma was $1150 \mathrm{~W}$. Signal integration was executed during a 15 -second period. Statistical processing of results was made using Microsoft Excel under $\mathrm{P}<0.05$.

\subsubsection{Method of Determining Organic Pesticides in Human Hair}

Standard solutions and spiked samples preparation: Standard solutions of eight pesticides were prepared by dissolving $20 \mathrm{mg}$ of each pesticide in $200 \mathrm{ml}$ hexane in a $200 \mathrm{ml}$ volumetric flask. The concentration of the stan-
Table 2. Hair hydrolysis program in the microwave system speedwave MWS-3+.

\begin{tabular}{cccccc}
\hline \multirow{2}{*}{ Parameters } & \multicolumn{5}{c}{ Step } \\
\cline { 2 - 6 } & 1 & 2 & 3 & 4 & 5 \\
\hline Temperature, ${ }^{\circ} \mathrm{C}$ & 160 & 190 & 190 & 100 & 100 \\
Pressure, bar & 30 & 30 & 30 & 0 & 0 \\
Time, min & 5 & 5 & 10 & 10 & 10 \\
Heating, min & 5 & 1 & 1 & 1 & 1 \\
Power, \% & 80 & 80 & 80 & 0 & 0 \\
\hline
\end{tabular}

dard stock solution was $0,1 \mathrm{mg} \cdot \mathrm{ml}^{-1}$. Additionally, the solution was diluted with hexane up to 100 times. Working standard solution of 10, 50, 100, 150 and $200 \mu \mathrm{g} \cdot \mathrm{g}^{-1}$ were prepared by adding the standard solution with volumes of 2, 10, 20, 30 and $40 \mathrm{ml}$ over the surface of $200 \mathrm{mg}$ head hair sample. Next, the spiked samples were allowed to keep in a covered Petri plate for two days. The solvent was then dried under vacuum and gaseous nitrogen. The spiked samples were extracted under the optimal SFE conditions (P, T and $\tau$ ) and analyzed to GC-MS. Recoveries were $85 \%$ to $110 \%$ with different pesticides. Three replications were considered for fortification [21].

Before the digestion procedure for the determination of organic pesticides, $200 \mathrm{mg}$ of the hair sample was cleansed with the help of sodium dodecyl sulfate and was comminuted with stainless steel scissors to homogenize. The spike sample was placed in a stainless steel extraction vessel with a volume of $12 \mathrm{ml}$ and the extraction vessel was placed in the thermostat. Additionally, as part of preparation for the main experiment, a brief $\mathrm{CO}_{2}$-extraction process was established for the purpose of additional sample purification and elimination of endogenous substances that may have caused distortions. For this, in the SFE instrument shown in Figure 2, the static (lasting for a period of five minutes) and dynamic (lasting equally, with discharge of $0.4 \mathrm{~g} \cdot \mathrm{min}^{-1}$ ) processing modes were performed in turns, with $\mathrm{T}=35^{\circ} \mathrm{C}$ and $\mathrm{P}=100$ bar.

The carbon dioxide taken from reservoir 1 , passed through drier filter 3 , which was filled with dehydrated silica gel. Afterwards, $\mathrm{CO}_{2}$ was cooled up to $268 \mathrm{~K}$ and was drawn up by pump 6 . The co-solvent that was used was passed from reservoir 12 with the help of pump 7 . After the carbon dioxide and co-solvent flows were mixed, the modified extractant moved to the extraction vessel 9 filled with hair. Furthermore, during the barbotage process of the extractant flow, the extract flowed through the collection vessel (organic solvent with volume $5 \mathrm{ml}$ in the V-like collection vessel 11) and extract solution in the correspondent organic solvent was formed. 


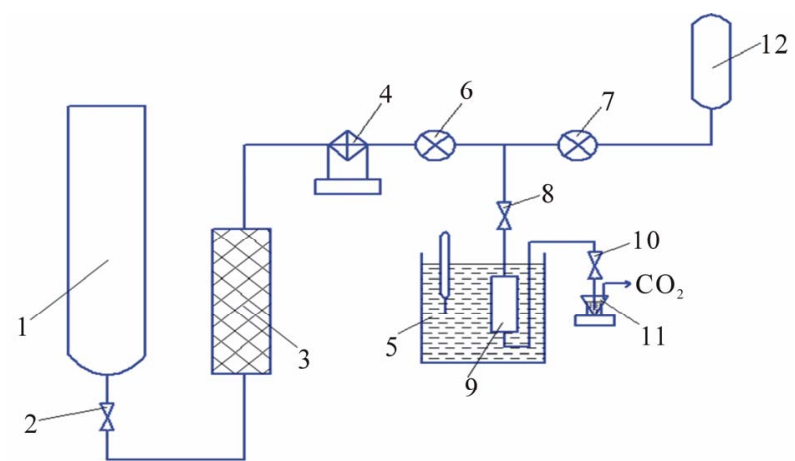

Figure 2. Schematic view of supercritical fluid extraction instrument: 1 -reservoir with $\mathrm{CO}_{2} ; 2,8,10$-valves; 3-drier filter; 4-cooling unit; 5-thermostat; 6, 7-pumps; 9-extraction vessel; 11 - collection vessel; 12 -reservoir with co-solvent.

As a result, the releasing carbon dioxide escaped outside.

The gas chromatographic analysis with mass spectrometry detector was performed on the DFS Thermo Electron Corporation (USA). The ion source was operated in the electron ionization mode $\left(\mathrm{EI} ; 70 \mathrm{eV}, 280^{\circ} \mathrm{C}\right)$. All mass spectra were obtained with the open-tubular column DB-5MS "Agilent" (length $30 \mathrm{~m}$, column diameter $0.254 \mathrm{~mm}$, film thickness $0.25 \mu \mathrm{m})$. Helium, at a flow-rate of $1.0 \mathrm{ml} \cdot \mathrm{min}^{-1}$, was used as carrier gas. The process of mass-spectrometric data was controlled by a computer running Xcalibur software. The injector port temperature was kept at $280^{\circ} \mathrm{C}$. The oven temperature program was as follows: $120^{\circ} \mathrm{C}$ held for a period of one minute, ramp to final temperature $280^{\circ} \mathrm{C}$ at $10^{\circ} \mathrm{C} \cdot \mathrm{min}^{-1}$, held for a period of 30 minutes. Sample injection was completed with flow split 1:20, using an injection volume of $1 \mu \mathrm{l}$. The mass spectra were registered in the mass range from $\mathrm{m} / \mathrm{z} 33$ up to 650 , respectively.

\section{RESULTS AND DISCUSSION}

\subsection{Organic Pesticides in Hair Samples}

\subsubsection{Supercritical $\mathrm{CO}_{2}$ Extraction}

The relationship between pesticides excretion and $\mathrm{P}, \mathrm{T}$, extraction time of SFE process $(\tau)$ were explored during this process. In Figure 3(a), the dependence of pesticides excretion on $\tau$ are shown. The maximum excretion speed for all researched pesticides started from the $\sim 60$ th minute. After a period of two hours, at a flow speed of 0.4 $\mathrm{g} \cdot \mathrm{min}^{-1}$, the excretion of pesticides remained nearly constant.

There was a considerable increase of the pesticides excretion level dependent on the temperature in the range of $30^{\circ} \mathrm{C}-45^{\circ} \mathrm{C}$ (Figure 3(b)).

The dependency of pesticides excretion on $\mathrm{P}$ at constant $\mathrm{T}$ and $\tau$ is shown in Figure 3(c). A monotonous growth of pesticides excretion with $\mathrm{P}$ growth in the range of $100-400$ bar is shown, respectively. However, the

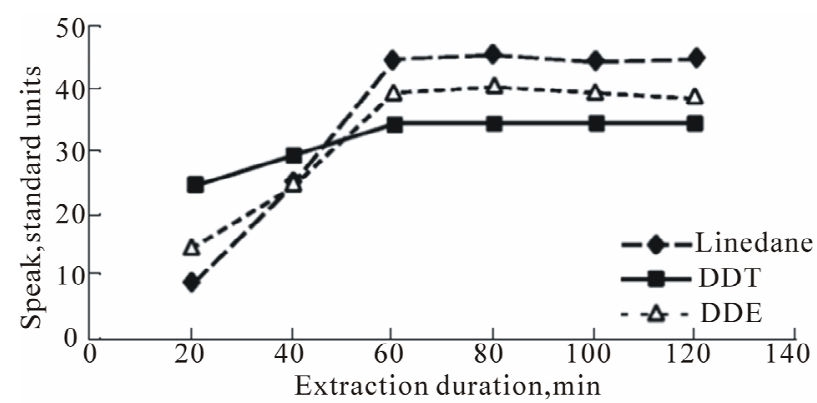

(a)

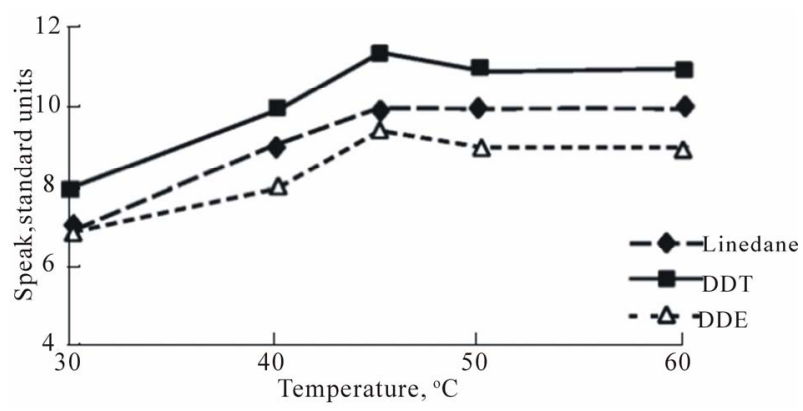

(b)

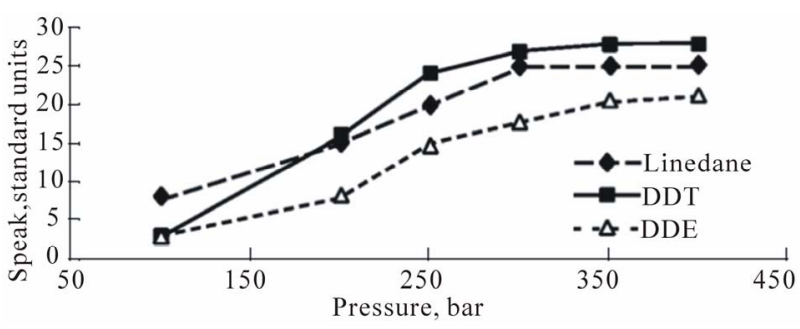

(c)

Figure 3. Graphs showing relationships between pesticides excretion from human hair ( $\mathrm{S}$ peak, standard units) and parameters ((a): $\tau$; (b): T; (c): P) of SFE process.

speed of this growth differs much within the intervals of $100-250$ bar and $250-350$ bar, respectively.

The results for the research of the influence of conditions on the pesticides excretion SFE process from hair provided a possibility to develop a method of detecting highly volatile and averagely volatile organic substances within the human hair.

A comparative analysis of SFE and LLE methods efficiencies for extracting the chlorine organic pesticide dichloro-diphenyl-trichloroethane (DDT) was studied. It is shown in Table 1, the SFE method has certain advantages over the LLE method in usage for extracting the chlorine organic pesticide DDT.

\subsubsection{GC-MS Analysis Extracts}

Method validation: The identification of the pesticides was performed by mass spectrometry detector and compared the retention times of the standards and the peaks. Peak confirmation is necessary because the chromatograms of real samples can present peaks corresponding to 
other contaminants or endogenous compounds that elute at the same retention times as the compound studied.

In order to determine the optimal conditions for the SFE process, concentrations of pesticides in the human hair by the SFE-GC/MS method with the external standard were researched. For this, the aliquots of pesticides solution in hexane or methanol with known concentrations were added to a batch weight of cleansed and fragmented hair prepared for extraction and analysis. As a result, the pesticides solution covered the hair and left in contact with it during a period of two days. After that, the solvent was dried under vacuum and gaseous nitrogen. The results showed that the variant of pure $\mathrm{CO}_{2}$ usage is optimal for determining such pesticides as hexachlorobenzene, lindane, butapon, p,p'DDE, p,p'DDT. However, in the case of dichlorvos, 2,4-D and chlorofos, better results were achieved with modification of supercritical carbon dioxide 5\% $\mathrm{MeOH}$ (see Table 3).

Recovery: Recovery studies of the head hair samples fortified at $10,50,100,150$ and $200 \mu \mathrm{g} \cdot \mathrm{g}^{-1}$ were performed (three replications). The recovery rates of OCPs and OPPs in human head hair were from $85 \%$ to $110 \%$ (Table 3). These findings were excellent, because of the extraction method used and found recoveries of drugs in human head hair were from $53 \%$ to $96 \%$ (Crimele et al., 1995).

Repeatability: The repeatability was determined by three injections of a standard solution made with the auto injector at $1 \mu 1$. Table 3 shows that the relative standard deviation obtained for retention time and peak area. Therefore, the repeatability of the chromatographic method was acceptable.

Linearity: Standard curves were made by computing regression lines of peak area of dichlorvos, chlorofos, hexachlorobenzene, lindane, butapon, p,p'DDE, p,p'DDT and 2,4-D after addition of 10 to $200 \mu \mathrm{g} \cdot \mathrm{g}^{-1}$ standards with three replications. The linear regressions were greater than 0.9861 (see Table 4).

Limits of detection (LOD) and quantification (LOQ): lowest LOD for the $200 \mathrm{mg}$ sample of head hair was 0.7 $\mu \mathrm{g} \cdot \mathrm{g}^{-1}$ with GC-MS. The observed lowest LOD undoubtedly viewing that maximum residue limit research could be successfully done in this laboratory.

A total of eight pesticides (dichlorvos, hexachlorobenzene, lindane, butapon, p,p'DDE, p,p'DDT, chlorofos, 2,4-D) were indentified within the hair of the Vietnamese test subjects (Table 5).

\subsection{Chemical Elements in Hair Samples}

A total of 28 chemical elements were detected within the hair samples of the Vietnamese test subjects by using the inductively coupled plasma atomic emission spectroscopy. Results are given in Table 6.

During the analysis of collected data shown in Table 6, it was discovered that there was an excess of lead concentration in the systems of both genders. With respect to the essential elements, there was lack of Se $(80 \%), \mathrm{Fe}$ (55\%), P (47\%). Except for excess lead, there was also excess aluminum in the hair with a concentration that was $56 \%$ above normal levels [4].

\subsection{Activity of NAT and CYP450}

The differentiation of Vietnamese test subjects based on the activity of CYP450 during research of the antipyrine oxidation phenotypes was separated into three groups: rapid $(23.3 \%)$, average $(50 \%)$ and slow types (26.7\%), respectively. Research also showed that, based on the activity of NAT in the human organism, testers can be subdivided into two groups: with rapid (62.9\%) and slow $\mathrm{N}$-acetylation phenotypes (37.1\%), respectively (see Table 7).

\subsection{Biomonitoring Xenobiotics in the Body of Vietnamese Test Subjects}

From a clinical point of view, it is interesting to ex-

Table 3. Percent recoveries of organic pesticides spiked to hair samples (percent recovery \pm standard deviation).

\begin{tabular}{|c|c|c|c|c|c|c|c|c|}
\hline Pesticides & Dichlorvos & $\begin{array}{c}\text { Hexachloro- } \\
\text { benzene }\end{array}$ & Lindane & Butapon & $\mathrm{p}, \mathrm{p}$ 'DDE & $\mathrm{p}, \mathrm{p}$ 'DDT & $2,4-\mathrm{D}$ & Chlorofos \\
\hline $\mathrm{TR}(\min )$ & 3.4 & 8.4 & 9.1 & 10.3 & 13.1 & 14.6 & 7.6 & 4.5 \\
\hline Spiked Conc. $\left(\mu \mathrm{g} \cdot \mathrm{g}^{-1}\right)$ & 50 & 50 & 100 & 150 & 50 & 50 & 50 & 100 \\
\hline $\operatorname{LLE}(n=4)$ & $57 \pm 10$ & $68 \pm 12$ & $72 \pm 11$ & $75 \pm 10$ & $67 \pm 8$ & $62 \pm 13$ & $10 \pm 3^{*}$ & $12 \pm 4^{*}$ \\
\hline $\begin{array}{c}\text { SFE: } \\
+ \text { pure } \mathrm{CO}_{2}(\mathrm{n}=4) \\
+ \text { +modification }\end{array}$ & $52 \pm 11$ & $89 \pm 17$ & $91 \pm 10$ & $92 \pm 8$ & $87 \pm 11$ & $85 \pm 13$ & $45 \pm 7$ & $56 \pm 14$ \\
\hline $\mathrm{CO}_{2}+\mathrm{MeOH}(5 \%)(\mathrm{n}=3)$ & $79 \pm 15$ & $81 \pm 20$ & $77 \pm 6$ & $85 \pm 15$ & $71 \pm 10$ & $75 \pm 9$ & $80 \pm 14$ & $84 \pm 7$ \\
\hline
\end{tabular}

*Pesticides loss due to poor solubility in a mixture of hexane-dichlormethane. 
Table 4. Linearity and detection limits of OCPs and OPPs.

\begin{tabular}{|c|c|c|c|c|}
\hline Pesticides & Range $\left(\mu \mathrm{g} \cdot \mathrm{g}^{-1}\right)$ & Calibration curve & $\gamma$ & $\operatorname{LOD}\left(\mu \mathrm{g} \cdot \mathrm{g}^{-1}\right)$ \\
\hline Dichlorvos & $10-200$ & $y=0.33 x+2.4$ & 0.9958 & 1.3 \\
\hline Hexachlorobenzene & $10-200$ & $y=0.122 x+0.8$ & 0.9918 & 0.7 \\
\hline Lindane & $10-200$ & $y=0.318 x-2.4$ & 0.9892 & 1.2 \\
\hline Butapon & $10-200$ & $y=0.544 x+2.2$ & 0.9927 & 1.2 \\
\hline $\mathrm{p}, \mathrm{p}$ 'DDE & $10-200$ & $y=0.332 x-3$ & 0.9929 & 0.9 \\
\hline $\mathrm{p}, \mathrm{p}$ 'DDT & $10-200$ & $y=0.19 x+0.6$ & 0.9942 & 0.9 \\
\hline 2,4-D & $10-200$ & $y=0.112 x-0.8$ & 0.9861 & 1.1 \\
\hline Chlorofos & $10-200$ & $y=0.113 x-0.6$ & 0.9966 & 1.3 \\
\hline
\end{tabular}

Table 5. The concentration of pesticides in the hair of Vietnamese test subjects.

\begin{tabular}{|c|c|c|c|c|c|c|c|c|c|c|c|c|c|c|c|c|c|c|c|c|c|c|}
\hline \multirow{2}{*}{ Pesticide } & \multirow{2}{*}{$\begin{array}{l}\text { Solvent for } \\
\text { collecting } \\
\text { extract }\end{array}$} & \multirow{2}{*}{ Conditions of SFE- } & \multicolumn{20}{|c|}{ Concentration of pesticides in hair samples $\left(\mu \mathrm{g} \cdot \mathrm{g}^{-1}\right)$} \\
\hline & & & 1 & 2 & 3 & 4 & 5 & 6 & 7 & 8 & 9 & 10 & 11 & 12 & 13 & 14 & 15 & 16 & 17 & 18 & 19 & 20 \\
\hline Dichlorvos & $\begin{array}{c}\mathrm{C}_{6} \mathrm{H}_{12}-\mathrm{CH}_{2} \mathrm{Cl}_{2} \\
(1: 3 \mathrm{v} / \mathrm{v})\end{array}$ & $\begin{array}{l}60 \min , 45^{\circ} \mathrm{C}, 350 \\
\text { bar, modified } \mathrm{CO}_{2}\end{array}$ & - & - & 34.8 & - & 115 & - & - & 70 & - & - & - & - & 8.2 & - & 15 & 11 & - & - & - & - \\
\hline $\begin{array}{l}\text { Hexachloro- } \\
\text { benzene }\end{array}$ & $\begin{array}{c}\mathrm{C}_{6} \mathrm{H}_{12}-\mathrm{CH}_{2} \mathrm{Cl}_{2} \\
(4: 1 \mathrm{v} / \mathrm{v})\end{array}$ & $\begin{array}{c}60 \mathrm{~min}, 45^{\circ} \mathrm{C} \\
350 \mathrm{bar} \text {, pure } \mathrm{CO}_{2}\end{array}$ & 14.3 & - & - & - & - & - & - & - & 3.2 & - & - & - & - & - & - & - & - & - & - & 5.1 \\
\hline Lindane & $\begin{array}{c}\mathrm{C}_{6} \mathrm{H}_{12}-\mathrm{CH}_{2} \mathrm{Cl}_{2} \\
(4: 1 \mathrm{v} / \mathrm{v})\end{array}$ & $\begin{array}{c}60 \mathrm{~min}, 45^{\circ} \mathrm{C}, \\
350 \text { bar, pure } \mathrm{CO}_{2}\end{array}$ & 56.7 & 39.1 & - & - & - & - & - & - & 2.5 & - & - & - & - & - & - & - & - & - & - & - \\
\hline Butapon & $\begin{array}{c}\mathrm{C}_{6} \mathrm{H}_{12}-\mathrm{CH}_{2} \mathrm{Cl}_{2} \\
(4: 1 \mathrm{v} / \mathrm{v})\end{array}$ & $\begin{array}{c}60 \mathrm{~min}, 45^{\circ} \mathrm{C} \\
350 \text { bar, pure } \mathrm{CO}_{2}\end{array}$ & - & 28.5 & - & - & - & 12.5 & - & - & - & - & - & - & - & - & 2 & - & - & - & - & - \\
\hline p,p'DDE & $\begin{array}{c}\mathrm{C}_{6} \mathrm{H}_{12}-\mathrm{CH}_{2} \mathrm{Cl}_{2} \\
(4: 1 \mathrm{v} / \mathrm{v})\end{array}$ & $\begin{array}{c}60 \mathrm{~min}, 45^{\circ} \mathrm{C}, \\
350 \text { bar, pure } \mathrm{CO}_{2}\end{array}$ & - & 16 & 11.4 & - & - & 75.4 & - & 8.2 & - & - & - & - & - & - & - & - & - & - & - & 9.8 \\
\hline p,p'DDT & $\begin{array}{c}\mathrm{C}_{6} \mathrm{H}_{12}-\mathrm{CH}_{2} \mathrm{Cl}_{2} \\
(4: 1 \mathrm{v} / \mathrm{v})\end{array}$ & $\begin{array}{c}60 \mathrm{~min}, 45^{\circ} \mathrm{C}, \\
350 \text { bar, pure } \mathrm{CO}_{2}\end{array}$ & 135.6 & - & 4.3 & - & - & - & 17 & 3.2 & - & - & - & - & 28 & - & - & - & - & - & - & - \\
\hline $2,4-\mathrm{D}$ & methanol & $\begin{array}{l}60 \min , 45^{\circ} \mathrm{C} \\
350 \mathrm{bar}, \\
\text { modified } \mathrm{CO}_{2}\end{array}$ & - & 52.1 & 18.2 & - & 48 & - & - & 34 & - & - & - & - & - & - & - & - & 2.8 & - & - & - \\
\hline Chlorofos & methanol & $\begin{array}{l}60 \mathrm{~min}, 45^{\circ} \mathrm{C} \\
350 \mathrm{bar}, \\
\text { modified } \mathrm{CO}_{2}\end{array}$ & - & - & - & - & - & - & - & - & - & - & - & 12 & - & - & - & - & - & - & - & - \\
\hline
\end{tabular}

-: No detection.

amine the interrelation between the ability of rapid acetylizers to oxidize medications slowly and, on the contrary, the ability of slow acetylizers to oxidize medications rapidly.

Phenotyping of 21 humans based on the acetylating type and of 20 humans based on the oxidizing type was studied. Comparative analysis was completed for the acetylating and oxidizing enzyme systems activity. It was discovered that the slow type of oxidizing is relevant to the rapid type of acetylating, and vice versa; and the average type of oxidizing may be relevant both to rapid and low NAT activities (see Table 8).

It is also important to note that concentrations of toxic and essential elements in the hair of Vietnamese people are different, dependent on the time of residence within
Russia. Almost all adult Vietnamese who have been living in Russia for a period of 15 to 25 years showed a progressive increase in the following chemical elements: $\mathrm{Zn}-1.5$ times, $\mathrm{Cu}-3$ times, $\mathrm{Mn}-8$ times, Mo-more than 5 times, $\mathrm{Ba}-2$ times, $\mathrm{Ga}-3$ times, $\mathrm{Ca}-5$ times, and $\mathrm{Al}-2.8$ times to acceptable physiological deviations accordingly for $50 \%, 62 \%, 73 \%, 47 \%, 52 \%, 50 \%, 65 \%$ and $70 \%$ of testers. The lack of essential Se was shown 4 times, and $\mathrm{P}-1.6$ times more frequently by young Vietnamese (living in Russia for 1 to 10 years). Lack of Se was shown by almost $89 \%$ of the older Vietnamese test subjects, and by half of the younger Vietnamese test subjects.

From the data shown in Table 9, it was evident that the greatest concentration of toxic elements was possessed 
Table 6. Results of chemical elements $\left(\mathrm{mg} \cdot \mathrm{kg}^{-1}\right)$ in the hair of Vietnamese test subjects residing in Russia $(\mathrm{n}=40, \mathrm{P}<0.05)$.

\begin{tabular}{|c|c|c|c|c|c|c|}
\hline \multirow{2}{*}{$\begin{array}{l}\text { Element } \\
\text { (line, } \mathrm{nm} \text { ) }\end{array}$} & \multicolumn{2}{|c|}{$\begin{array}{l}\text { Biological acceptable level } \\
\text { (Skalnuj and Rudakov 2003) }\end{array}$} & \multicolumn{2}{|c|}{ Men } & \multicolumn{2}{|c|}{ Women } \\
\hline & Lower limit & Upper limit & Ages $18-25$ & Ages 35 - 55 & Ages $18-25$ & Ages $35-55$ \\
\hline Se $(169,090)$ & 0.5 & 1.5 & $0.30 \pm 0.05$ & - & $0.17 \pm 0.01$ & - \\
\hline $\mathrm{Fe}(259,940)$ & 3 & 75 & $14 \pm 5$ & $13.8 \pm 4.2$ & $16 \pm 7$ & $10 \pm 1.2$ \\
\hline $\mathrm{Zn}(206,200)$ & 100 & 250 & $119 \pm 20$ & $195 \pm 15$ & $133 \pm 12$ & $194 \pm 13$ \\
\hline $\operatorname{Si}(212,412)$ & - & - & $27 \pm 9$ & $36.1 \pm 8.5$ & $30 \pm 6$ & $37 \pm 11$ \\
\hline $\mathrm{Cu}(324,754)$ & 7.5 & 80 & $8 \pm 1.1$ & $24 \pm 5$ & $7 \pm 0.9$ & $27 \pm 7$ \\
\hline $\operatorname{Mn}(257,610)$ & 0.05 & 2 & $0.6 \pm 0.2$ & $6.3 \pm 4.2$ & $2.6 \pm 0.5$ & $5.5 \pm 2.1$ \\
\hline Co $(228,616)$ & 0.05 & 0.5 & $0.05 \pm 0.01$ & - & $0.07 \pm 0.02$ & - \\
\hline $\mathrm{Cr}(267,716)$ & 0.1 & 2 & $5.33 \pm 0.02$ & $2.3 \pm 1.1$ & $5.39 \pm 0.02$ & $3.2 \pm 1.5$ \\
\hline $\mathrm{V}(292,402)$ & 0.005 & 0.5 & $0.37 \pm 0.03$ & - & $0.15 \pm 0.04$ & - \\
\hline $\operatorname{Li}(670,784)$ & 0.01 & 0.25 & $0.07 \pm 0.01$ & - & $0.22 \pm 0.02$ & - \\
\hline Mo $(202,030)$ & 0.02 & 0.15 & $0.18 \pm 0.01$ & $1.23 \pm 0.12$ & $0.19 \pm 0.04$ & $1.1 \pm 0.2$ \\
\hline $\mathrm{Ba}(455,403)$ & - & - & $1.5 \pm 0.2$ & $3.1 \pm 1.2$ & $3.7 \pm 0.4$ & $2.5 \pm 1.1$ \\
\hline $\mathrm{Ga}(294,364)$ & - & - & $0.9 \pm 0.05$ & $1.2 \pm 0.00$ & $0.2 \pm 0.01$ & $1.5 \pm 0.00$ \\
\hline $\operatorname{Sr}(421,552)$ & 0.5 & 5 & $2.8 \pm 0.3$ & $16.4 \pm 4.2$ & $13.4 \pm 1.1$ & $13.6 \pm 5.3$ \\
\hline B $(249,773)$ & - & - & $5.6 \pm 0.7$ & $2.65 \pm 1.50$ & $5.8 \pm 0.0$ & $2.1 \pm 0.3$ \\
\hline $\mathrm{W}(224,875)$ & - & - & $0.07 \pm 0.01$ & $0.06 \pm 0.00$ & $0.01 \pm 0.00$ & - \\
\hline $\operatorname{Mg}(285,213)$ & 19 & 163 & $37 \pm 5$ & $155 \pm 42$ & $129 \pm 18$ & $121 \pm 35$ \\
\hline $\mathrm{Ca}(317,993)$ & 200 & 2000 & $399 \pm 25$ & $2180 \pm 756$ & $989 \pm 83$ & $1675 \pm 325$ \\
\hline $\mathrm{Na}(589,592)$ & 18 & 1720 & $285 \pm 73$ & $461 \pm 101$ & $151 \pm 44$ & $331 \pm 85$ \\
\hline $\mathrm{P}(178,284)$ & 75 & 200 & $74 \pm 6$ & $46 \pm 11$ & $65 \pm 5$ & $41 \pm 14$ \\
\hline $\mathrm{K}(766,490)$ & 150 & 663 & $55 \pm 12$ & $71 \pm 21$ & $33 \pm 8$ & $72 \pm 15$ \\
\hline $\mathrm{Al}(396,152)$ & 1 & 10 & $10.2 \pm 2.3$ & $28 \pm 5$ & $8.2 \pm 2.9$ & $25 \pm 6$ \\
\hline $\mathrm{Cd}(214,440)$ & 0.05 & 0.25 & $0.06 \pm 0.02$ & - & $0.04 \pm 0.01$ & - \\
\hline $\mathrm{Pb}(220,353)$ & 0.1 & 8 & $11.2 \pm 3.5$ & - & $10.5 \pm 1.8$ & $8.1 \pm 1.1$ \\
\hline Sn $(189,989)$ & 0.05 & 1.5 & $0.19 \pm 0.03$ & - & $0.34 \pm 0.04$ & - \\
\hline Ni $(341,476)$ & 0.1 & 2 & $0.94 \pm 0.02$ & $0.96 \pm 0.12$ & $1.52 \pm 0.30$ & $0.93 \pm 0.22$ \\
\hline $\operatorname{Ti}(323,452)$ & 0.018 & 14 & $1.0 \pm 0.08$ & $9.3 \pm 1.5$ & $1.4 \pm 0.02$ & $4.7 \pm 1.2$ \\
\hline $\mathrm{Ag}(328,068)$ & - & - & $0.05 \pm 0.00$ & - & $0.009 \pm 0$ & - \\
\hline
\end{tabular}

by people with the slow NAT phenotype. This was confirmed by the greatest values of the median of $\mathrm{Ni}, \mathrm{Pb}, \mathrm{Cd}$ concentration in the hair, as well as high indexes of minimum and maximum values, and considerable rate of people that exceeded the biological permissible level of the researched metals. As far as some other toxic or potentially toxic elements were concerned ( $\mathrm{Sn}, \mathrm{Ti}, \mathrm{Ag} . .$.$) ,$ there either has been found no considerable deviations, or where no reference values were available.

During the analysis of the results of determining the concentration of pesticides in the hair by the SFEGC/MS method under the abovementioned optimal regimen conditions $\left(\mathrm{P}=350\right.$ bar, $\left.\mathrm{T}=45^{\circ} \mathrm{C}, \tau=60 \mathrm{~min}\right)$ showed that people with a weak anti-oxidating system 
Table 7. The parameters of test markers excretion in the biological fluids of Vietnamese test subjects $(n=65$, Sr in brackets).

\begin{tabular}{cccc}
\hline \multirow{2}{*}{ Metabolism } & Phenotype & Biomarkers & Probability \\
\cline { 3 - 3 } & & excretion & distribution, $\mathrm{P}$ \\
\hline \multirow{2}{*}{ A-Oxidation (Phase I) } & +rapid & in 12 hours, $\mu \mathrm{g}$ & $\mathrm{P}<0.001$ \\
& +average & $3.27 \pm 0.51(0.02)$ & $\mathrm{P}<0.001$ \\
B-N-acetylation (Phase II) & +slow & $11.28 \pm 2.08(0.04)$ & $\mathrm{P}<0.05$ \\
& +rapid & $26.15 \pm 4.76(0.02)$ & $\mathrm{P}<0.05$ \\
\hline
\end{tabular}

Table 8. The activity of $\mathrm{N}$-acetyltransferase in the groups of slow, average and rapid oxidizing phenotypes (healthy testers, $\mathrm{n}=41, \mathrm{Sr}$ in brackets).

\begin{tabular}{|c|c|c|c|c|}
\hline $\begin{array}{l}\text { Oxidation } \\
\text { phenotype }\end{array}$ & $\begin{array}{l}\text { Excretion of antipyrine in } \\
12 \text { hours, } \mu \mathrm{g}\end{array}$ & $\begin{array}{l}\text { Probability } \\
\text { distribution }\end{array}$ & $\begin{array}{l}\text { Activity of } \mathrm{N} \text {-acetyltransferase } \\
\text { (fraction dose INH, \%) }\end{array}$ & $\begin{array}{l}\text { Probability } \\
\text { distribution }\end{array}$ \\
\hline Rapid & $2.56 \pm 0.82(0.02)$ & \multirow{3}{*}{$\mathrm{P}<0.001$} & $10.75 \pm 1.25(0.03)$ & \multirow{3}{*}{$\mathrm{P}<0.05$} \\
\hline Average & $9.15 \pm 2.05(0.03$ & & $6.52 \pm 3.21(0.03)$ & \\
\hline Slow & $25.27 \pm 5.65(0.03)$ & & $4.25 \pm 1.10(0.05)$ & \\
\hline
\end{tabular}

Table 9. The content of toxic elements in the hair of individuals with different NAT phenotypes.

\begin{tabular}{|c|c|c|c|c|c|c|}
\hline \multirow{3}{*}{ Elements } & \multicolumn{3}{|c|}{ Slow NAT phenotype } & \multicolumn{3}{|c|}{ Rapid NAT phenotype } \\
\hline & median, & \multirow{2}{*}{$\min -\max , \mu \mathrm{g} \cdot \mathrm{g}^{-1}$} & \multirow{2}{*}{$\% \uparrow$} & median, & \multirow{2}{*}{$\min -\max , \mu \mathrm{g} \cdot \mathrm{g}^{-1}$} & \multirow{2}{*}{$\% \uparrow$} \\
\hline & $\mu \mathrm{g} \cdot \mathrm{g}^{-1}$ & & & $\mu \mathrm{g} \cdot \mathrm{g}^{-1}$ & & \\
\hline $\mathrm{Ni}$ & 0.99 & $0.85-1.22$ & 0 & 0.88 & $0.8-0.93$ & 0 \\
\hline $\mathrm{Pb}$ & 11.67 & $7.33-14.7$ & 72 & 7.92 & $6.33-12.0$ & 25 \\
\hline $\mathrm{Cd}$ & 0.05 & $0.04-0.08$ & 0 & 0.04 & $0.03-0.07$ & 0 \\
\hline $\mathrm{Al}$ & 9.5 & $6.2-12.5$ & 50 & 10.5 & $8.4-12.2$ & 25 \\
\hline
\end{tabular}

(heavy deficiency of Se, heavy risk of cancer genesis due to low detoxification speed) have a high concentration of OCPs within their hair (samples 1, 2, 3 and 5 in Table 5).

\section{CONCLUSION}

Methods of supercritical fluid $\mathrm{CO}_{2}$ extraction followed by gas chromatography coupled to mass spectrometry determination of organic pesticides and AES-ICP determination of 28 chemical elements from human hair as well as determination signs of genetic predilection to the effect of toxins in human body were explored. These methods resulted in the possibility of making an express estimation of pesticides and the concentration of similar organic substances in other biological objects as well. From a practical point of view, its importance is connected with the fact that it reflects all of the most influential human impacts in the environment and gives us the possibility to choose correctly the priorities and directions of activity in improving the ecological situation around us. Moreover, we could have a great impact on the diagnostic, prognostic and treatment of patients with different acute and chronic diseases.

\section{ACKNOWLEDGEMENTS}

The authors wish to thank Dr. R. Musin for stimulating discussions and for providing access to chromatography-mass-spectrometry analysis.

\section{REFERENCES}

[1] Le, P.C., Evgen'ev, M.I. and Gumerov, F.M. (2012) Determination of pesticides in the hair of Vietnamese by means of supercritical $\mathrm{CO}_{2}$ extraction and GC-MS analysis. The Journal of Supercritical Fluid, 61, 86-91. doi:10.1016/j.supflu.2011.09.014

[2] Evgenev, M.I., Garmonov, S.Y., Evgeneva, I.I., Goryunova, S.M., Pogoreltsev, V.I. and Levinson, F.S. (1998) Reversed-phase liquid chromatographic determination of isoniazide in human urine as a test of the genetically predetermined type of biotransformation by acetylation. $\mathrm{Ta}$ lanta, 47, 891-898. 
doi:10.1016/S0039-9140(98)00166-0

[3] Covaci, A., Tutudaki, M., Tsatsakis, A.M. and Scepens, P. (2002) Hair analysis: Another approach for the assessment of human exposure to selected persistent organochlorine pollutants. Chemosphere, 46, 413-418. doi:10.1016/S0045-6535(01)00065-0

[4] Skalnuj, A.V. and Rudakov, I.A. (2003) Bioelements in medicine. Moscow, 272.

[5] Le, P.C. and Evgen'ev, M.I. (2010) Polymorphisms of metabolic systems in the Vietnamese community in Russia. Journal of Science and Development of Danang City, 153, 23-26.

[6] Cholodov, L.E. and Yakovlev, V.P. (1985) Clinical Pharmacokinetics. Moscow, 191.

[7] Nebert, D.W. and Roe, A.L. (2001) Ethnic and genetic differences in metabolism genes and risk of toxicity and cancer. Science of the Total Environment, 274, 93-102. doi:10.1016/S0048-9697(01)00732-X

[8] Borella, P., Rovesti S., Caselgrandi, E. and Bargellini, A. (1996) Quality control in hair analysis: A systematic study on washing procedures for trace element determination. Mikrochim Acta, 123, 271-280. doi:10.1007/BF01244400

[9] Evans, G.J. and Jervis, R.E. (1987) Hair as a bio-indicator: Limitations and complications in the interpretation of results. Journal of Radioanalytical and Nuclear Chemistry, 110, 613-625. doi:10.1007/BF02035550

[10] Tutudaki, M., Tsatsakis, A.M. and Covaci, A. (2001) Hair analysis: An alternative methods of assessing exposure to organochlorine pollutants. Toxicology, 164, 85-86.

[11] Bogdanov, A.V., Glazkov, I.N., Polenova, T.V., Marutsenko, I.V. and Revel'skii, I.A. (2007) Determination of organic compounds in human hair. Journal of Analytical Chemistry, 61, 936-951. doi:10.1134/S1061934806100029

[12] Dauberschmidt, C. and Wennig, R. (1998) Organochlorine pollutants in human hair. Journal of Analytical Toxicology, 22, 610-611.

[13] Glazkov, I.N., Revelsky, I.A., Efimov, I.P. and Zolotov,
Y.A. (1999) Supercritical fluid extraction of water samples containing ultratrace amounts of organic micropollutants. Journal of Microcolumn Separations, 11, 729-736. doi:10.1002/(SICI)1520-667X(1999)11:10<729::AID-M CS6>3.0.CO;2-2

[14] Hashimi, A.A., Krishnan, S.S. and Jervis, R.E. (1992) Human hair as a pollutant dosimeter. Journal of Radioanalytical and Nuclear Chemistry, 161, 171-180. doi:10.1007/BF02034890

[15] Hawthorne, S.B., Miller, D.J., Nivens, D.E. and White, D.C. (1992) Supercritical-fluid extraction of polar analytes using in situ chemical derivatization. Analytical Chemistry, 64, 405-412. doi:10.1021/ac00028a015

[16] Neuber, K., Merkel, G. and Randow, F.F.E. (1999) Indoor air pollution by lindane and DDT indicated by head hair samples of children. Toxicology Letters, 107, 189-192. doi:10.1016/S0378-4274(99)00046-6

[17] Schramm, K.W. (1997) Hair: A matrix for non-invasive biomonitoring of organic chemicals in mammals. Bulletin of Environmental Contamination \& Toxicology, 59, 396-402. doi:10.1007/s001289900491

[18] Crimele, V., Kintz, P., Majdalani, R. and Mangin, P. (1995) Supercritical fluid extraction of drugs in drug addict hair. Journal of Chromatography B, 673, 173-181. doi:10.1016/0378-4347(95)00281-7

[19] Mohammad, A.R., Omar, D., Islam, M.Z., Morshed, M.M. and Rashid, K.N. (2010) Supercritical fluid extraction and quantification of chlorpyrifos insecticides in fresh vegetables by gas chromatography with electron capture detection. Agriculture and Biology Journal of North America, 4, 548-555.

[20] Nebert, D.W. and Dalton, T.P. (2006) The role of cytochrome P450 enzymes in endogenous signalling pathways and environmental carcinogenesis. Nature Reviews Cancer, 12, 947-960. doi: $10.1038 / \mathrm{nrc} 2015$

[21] Society of Hair Testing (2004) Recommendations for hair testing in forensic cases. Society of Hair Testing. Forensic Science International, 145, 83-84. doi:10.1016/j.forsciint.2004.04.022 